\title{
Chemical pneumonitis from aspiration of rash protector spray
}

\author{
Valerie Ramsey* \\ Global Regulatory Affairs, C.B. Fleet Company Inc., Lynchburg, VA, USA
}

Received 14 September 2012

Accepted 19 September 2012

Dear Editor,

C.B. Fleet Company, Inc. (C.B. Fleet) read the case report authored by The et al. [1] with great interest. As the owner and marketer of Boudreaux's Rash Protector ${ }^{\mathrm{TM}}$ Spray, as well as many other over-thecounter (OTC) drug products, C.B. Fleet agrees that the prevention of inappropriate or accidental misuse of OTC products is important and of concern. However, we must point out incorrect information in the article relative to the labeling of the rash protector spray product and relative to federal regulations for labeling of all OTC drug products.

The article incorrectly states that the rash protector spray product container did not list inactive ingredients. The labeling for this product has always included a complete list of both the active and inactive ingredients, as per requirements of the United States Food and Drug Administration (FDA) regulations for OTC drug products.

Also, in response to the conclusion noted in the article that manufacturers of OTC drug products should be required to list all ingredients, both active and inactive, C.B. Fleet would like to clarify that this requirement already exists, as noted above, and has existed for more than a decade. Specifically, title 21 sections $\$ 201.66(c)(2)$ and 201.66(c)(8) of the Code of Federal Regulations detail the FDA requirements to list each active ingredient and each inactive ingredient on the outside container or immediate retail package for all OTC products. [2]

C.B. Fleet would also like to note that we have spoken to the author of the article and confirmed and agreed that incorrect information was mistakenly included in the article. C.B. Fleet remains committed to supplying safe, effective, and compliant products and we appreciate the opportunity to note this correction.

\section{References}

[1] The TG, Parikh P, Jonna S. Chemical pneumonitis from aspiration of rash protector spray. J Pediatr Intensive Care 2012;1(3): 165-8.

[2] U.S. Food and Drug Administration, Department of Health and Human Services. CFR - Code of Federal Regulations Title 21 [Internet]. Silver Spring (MD): U.S. Food and Drug Administration; Labeling requirements for over-the-counter drugs, Section 201.66 Format and content requirements for OTC drug product labeling; [updated 2012 Apr 1; cited 2012 Sep 13]; [about 9 screens]. Available from http://www.accessdata.fda. gov/scripts/cdrh/cfdocs/cfcfr/CFRSearch.cfm?fr=201.66.

*Address for correspondence: Valerie Ramsey, Global Regulatory Affairs C.B. Fleet Company, Inc., 4615 Murray Place, Lynchburg, VA 24502, USA. Tel.: +1 434528 4000; E-mail: ramseyv@ cbfleet.com. 